\title{
Cultivation of Students' Autonomous Learning Ability in Application-oriented Universities
}

\author{
Lingling Lou \\ School of English Language, Zhejiang Yuexiu University, Shaoxing, Zhejiang, 312000, China
}

\begin{abstract}
In the knowledge society nowadays, the responsibility of education is not only to impart knowledge to students but also to enable students to have the ability of autonomous learning. Autonomous learning ability is the foundation of all kinds of abilities. Improving college students' autonomous learning ability plays an important role in cultivating high-quality talents and realizing their all-around development. Based on a brief introduction of the connotation of autonomous learning, this paper starts by discussing the necessity of cultivating college students' autonomous learning ability. Then, combined with the questionnaire survey, the paper analyzes the current status of students' autonomous learning ability in application-oriented universities, discusses the deep-seated reasons for undergraduates' lack of autonomous learning ability, and puts forward some countermeasures to cultivate college students' autonomous learning ability.
\end{abstract}

Index Terms - autonomous learning ability, cultivation, application-oriented universities

\section{INTRODUCTION}

\section{A. Background Information}

With the rapid development of science and technology and people's constant thirst for knowledge, network information technology is more and more used in education. The outbreak of COVID-19 in January 2020 has accelerated the integration of the Internet and education. Affected by the epidemic, teachers and students cannot return to the campus for offline learning. Therefore, the online teaching models combined with MOOCs or micro-lectures have been widely promoted, which also set higher requirements for students' autonomous learning ability. In the practice of online teaching, it is found that although teachers have adopted various teaching methods and teaching modes to carry out flexible online teaching, students' learning enthusiasm and learning effect are not ideal. The deep-seated reason behind this phenomenon is that students' actual autonomous learning ability is not consistent with teachers' expectations of students' autonomous learning ability. In other words, students' autonomous learning ability is seriously insufficient.

Therefore, to achieve the ideal effect of online teaching, we need first cultivate students' autonomous learning ability. With the improvement of students' autonomous learning ability, they can effectively use various teaching resources to carry out autonomous learning according to their own learning situation, learn to discover and solve problems in the learning process, and finally realize the internalization of knowledge and the acquisition of ability. In fact, the cultivation of students' autonomous learning ability is not only beneficial to their academic development but also crucial to their future career development and comprehensive quality cultivation.

\section{B. Connotation of Autonomous Learning}

Many scholars at home and abroad have defined the connotation of autonomous learning. Henry Holec (1981) first introduced the concept of autonomous learning into foreign language teaching. He defined autonomous learning as the ability of learners to be responsible for their own learning, that is, the ability of students to learn by themselves. And in this process, learners should determine their learning objectives and learning contents, choose appropriate learning methods according to their condition, try to solve or consult others to solve various problems in learning, and in the end make an objective evaluation of their learning process. Since then, many scholars, such as Dickinson and Littlewood, have defined the connotation of autonomous learning according to their research directions. Dickinson (1995) thought that autonomous learning is not only a kind of learning attitude but also an independent learning ability; Littlewood (1996) believed that autonomous learning is the ability of learners to acquire knowledge independently without relying on teachers.

In China, Professor Xu has done a lot of researches in this field. Combining with the practice of College English teaching, she (2004) put forward that college students' autonomous English learning ability should cover five aspects: 1) understanding teachers' teaching objectives and requirements; 2) establishing learning objectives and making learning plans; 3) making effective use of their learning strategies; 4) monitoring the use of learning strategies; 5) evaluating the whole learning process. From the above five aspects of self-learning ability, it can be seen that in order to have a strong self-learning ability, students must have a strong sense of self-learning, clear learning objectives, good autonomous learning habits, and strong self-monitoring ability. 


\section{NeCESSity of CUltivating College Students’'Autonomous LeARning Ability}

\section{A. Cultivating Students' Autonomous Learning Ability Is an Important Goal of Undergraduate Curriculum Reform}

With the continuous progress of society and the rapid development of science and technology, teaching methods should also be changed accordingly. The Implementation Opinions of the Ministry of Education on the Construction of First-class Undergraduate Courses (Ministry of Education of the People's Republic of China, 2019) clearly pointed out that innovative teaching methods should be adopted to improve the teaching effect. On the one hand, teachers are required to perfect their teaching design and try to eliminate the phenomenon of simply imparting knowledge while neglecting the development of students' competence and overall quality; on the other hand, they should also strive to strengthen the deep integration of modern information technology with education and put an end to the simplification and formalization of information technology application. In the teaching process, the interaction between teachers and students, students and students should be strengthened, students' innovative thinking and critical thinking ability should be cultivated, their independent learning ability should be enhanced, and the traditional "cramming" way of teaching should be changed into the student-oriented "participating learning".

The traditional teaching method is teacher-centered, which overemphasizes the teaching method and ignores the importance of the cultivation of students' learning methods. This kind of "cramming" teaching stifles not only students' interest and enthusiasm in autonomous learning, but also their innovation capability. If things go on like this, students will be used to passively and mechanically accepting knowledge, rather than actively exploring and discovering knowledge by themselves. This is obviously not conducive to students' academic progress, and may even backfire, seriously hindering the all-around development of students.

In a word, cultivating students' autonomous learning ability and enhancing their learning initiative are of great importance in undergraduate curriculum reform.

\section{B. Cultivating Students' Autonomous Learning Ability Is an Objective Need for College Students to Realize Their Own Development}

First of all, good autonomous learning ability is an important prerequisite for college students to improve their learning effect. Students with strong autonomous learning ability have more advantages in mastering and understanding knowledge than those who are immersed in mechanical learning. They can better understand and internalize new knowledge, and effectively apply it into practice, which is also in line with the characteristics of deep learning. Only when learners understand and master knowledge, can they apply the knowledge to practice and form their own knowledge structure and thinking ability.

Secondly, good self-learning ability is an inevitable requirement for the long-term development of college students. With the rapid development of science and technology in today's society, if we want to keep up with the pace of the times, we must keep the habit of lifelong learning. Without the self-learning ability, life-long learning is impossible, and the future development of individuals will be greatly limited. Therefore, only when college students change their wrong ideas, truly realize that learning is their own business, and turn "want me to learn" into "I want to learn", can they become the masters of learning and realize their sustainable development.

Thirdly, good autonomous learning ability is the basic element for innovative talents. Innovation has a decisive impact on the future development of a country and it is the premise of national rejuvenation. The current social development needs innovative talents. Innovation is the passport to enter the new era, the soul of a nation for survival, and the quality that a high-tech talent must possess. If students lack the ability of autonomous learning, their creativity will be out of the question. Autonomous learning ability is the prerequisite and foundation of creativity. Therefore, only by giving full play to students' autonomous learning and self-inquiry ability can students' innovative quality be cultivated.

To sum up, autonomous learning ability is a basic quality that contemporary college students must possess. It can not only help students improve their academic performance, but also make them feel the fun of learning, so as to stimulate their subjective initiative in learning, enhance their sense of innovation, and help them better adapt to the needs of social development.

\section{InVESTIGATION OF THE CURRENT StATUS OF STUDENTS’ AUTONOMOUS LEARNING ABILITY IN APPLICATION-ORIENTED UNIVERSITIES}

To have a comprehensive view of the development status of students' autonomous learning ability in application-oriented universities, the author conducted a questionnaire survey among some students on their autonomous learning ability in Zhejiang Yuexiu University. According to the discussion of the connotation of autonomous learning in chapter 1, this survey will focus on the four dimensions of the connotation of autonomous learning: whether the awareness of autonomous learning is strong, whether the goals of autonomous learning are clear, whether the habits of autonomous learning are developed and whether the ability of self-monitoring is possessed.

\section{A. Methodology}

\section{Research object}


The objects involved in this research are some students in the English School of Zhejiang Yuexiu University. According to the principle of stratified sampling, 200 students were randomly selected from 2257 students in the School of English Language to participate in the questionnaire survey. To make the sample more representative, the number of students should be roughly equal in gender structure and major background. In terms of the gender structure, there were 105 girls (accounting for 52.5\%) and 95 boys (accounting for 47.5\%); in terms of major background, the number of students in English major was 78, accounting for 39\%; the number of students in business English major was 54, accounting for $27 \%$; and the number of students in translation major was 68 , accounting for $34 \%$.

2. Research instrument

The research tool used in this study is a questionnaire survey. The questionnaire was designed by referring to other relevant questionnaire designs and combining them with the actual situation of students in application-oriented universities. The questionnaire consisted of two parts, with a total of 16 questions in four categories. The first part of the questionnaire was the basic information of the objects, and the second part was the main questions of the questionnaire. To have a deeper understanding of the status quo of students' autonomous learning ability in application-oriented universities, all the questions were designed on the basis of the connotation of autonomous learning, and the investigation was mainly carried out around the four dimensions of the development of autonomous learning ability. Some of the questions in the questionnaire were single-choice questions in the form of Likert scale, while others were multiple-choice questions to investigate their understanding of autonomous learning and their common practices in cultivating autonomous learning ability. The higher the score, the better the development status of autonomous learning ability.

After the questionnaire design was completed, a pre-survey was first conducted among a small group of students, and the students who participated in the pre-survey were asked to give suggestions or opinions on the questionnaire. And the results were analyzed. On this basis, the questionnaire was revised, and the final questionnaire came into being. The questionnaire survey was conducted in the College of English Language, Zhejiang Yuexiu University. A total of 200 questionnaires were distributed and 198 valid questionnaires were returned, with an effective rate of $99 \%$. All the data obtained from the single-choice questions in the questionnaire were analyzed with SPSS statistical software to calculate the mean value, and the answers to the multiple-choice questions in the questionnaire were also statistically calculated.

\section{B. Research Results and Analysis}

\section{Awareness of autonomous learning}

The dimension of self-learning awareness mainly aims to investigate students' self-evaluation of their development of self-learning ability. The survey on the dimension of self-learning awareness includes 5 aspects: students' understanding of the connotation of autonomous learning, the degree of students' fondness of autonomous learning, students' understanding of the importance of autonomous learning, the degree of students' satisfaction with their own autonomous learning ability and students' awareness of their own potential for autonomous learning.

There are five questions in this part of the questionnaire, all of which are single-choice questions. The results are shown in the figure below.

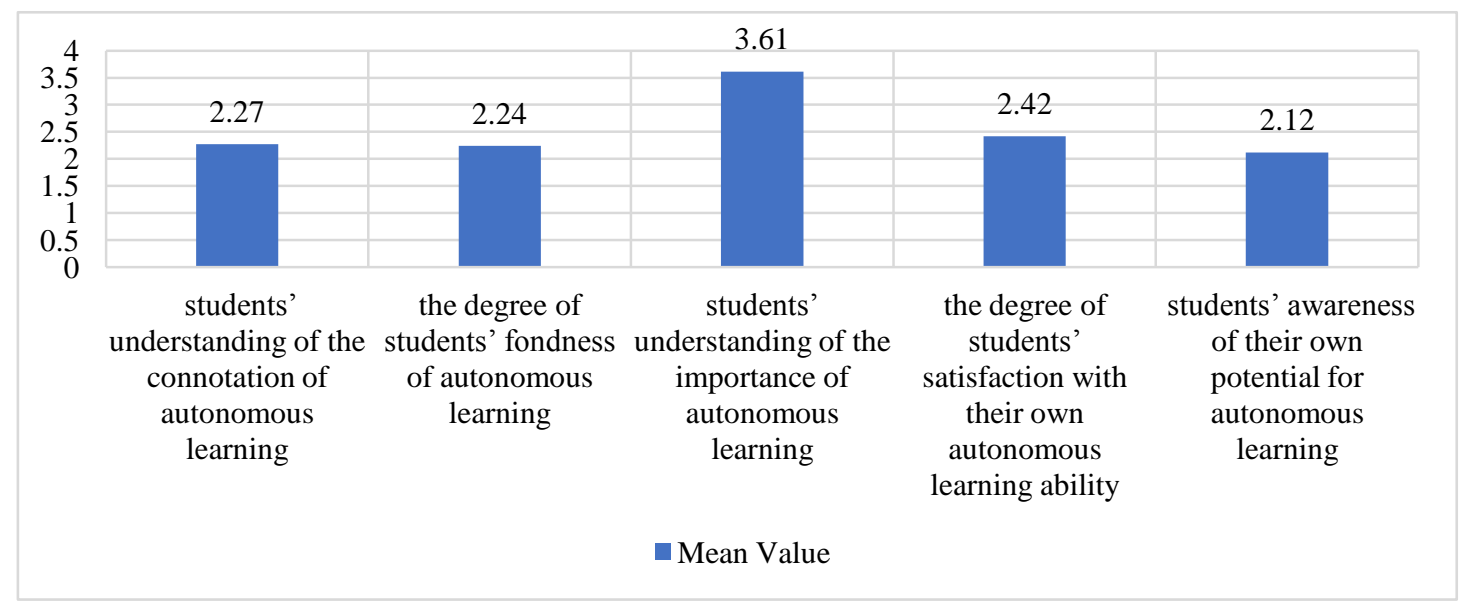

Figure 1 Investigation Results of the First Dimension

It can be seen from the results in Figure 1 that students generally had insufficient understanding of the connotation of autonomous learning (39.4\% of the objects chose "unclear" and $25.8 \%$ of the objects chose "very unclear"), and they did not like autonomous learning very much (only 30 students chose "like" or "strongly like", which only accounted for $15.2 \%$; meanwhile, $29.8 \%$ of the objects chose "dislike" and $32.8 \%$ chose "strongly dislike"). However, students were generally aware of the importance of independent learning (only 22.2\% of the students thought that autonomous learning was "unimportant" or "very unimportant"). Besides, students were generally not satisfied with their self-learning ability (the number of students who chose "satisfied" or "very satisfied" was only 34); to make matters 
worse, $71.7 \%$ of the students believed that there was little room for the development of their autonomous learning ability.

All in all, the above data show that most of the students do not have a strong sense of autonomous learning. Although they realize the importance of autonomous learning, most students don't like and are not willing to carry out autonomous learning at all, regarding that they have a poor academic foundation and do not have the ability to learn autonomously.

2. Goals of autonomous learning

The dimension of autonomous learning goals mainly examines whether the objects have a clear concept of learning objectives. The survey on the dimension of autonomous learning goals mainly includes 3 aspects: whether students have a clear understanding of the teachers' teaching objectives and requirements; whether students can clearly define their learning objectives and formulate corresponding learning plans, and whether they have the confidence to achieve the established learning objectives.

There are three questions in this part of the questionnaire, all of which are single-choice questions. The survey results are shown in the figure below.

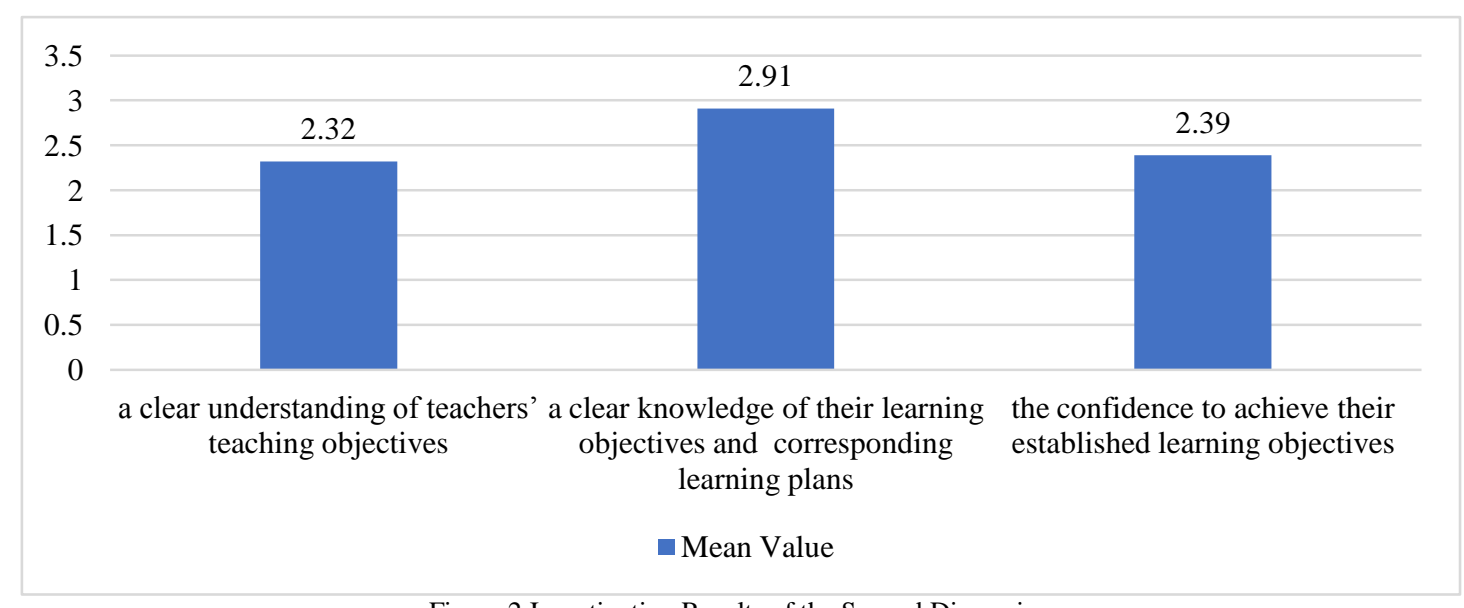

Figure 2 Investigation Results of the Second Dimension

It can be seen from the results in Figure 2 that in the process of autonomous learning, students generally did not have a clear understanding of the teachers' teaching objectives and requirements $(31.3 \%$ of the objects chose "unclear", and $28.3 \%$ of the objects chose "very unclear"); most of the students also indicated that they were unable to determine their learning objectives and formulate corresponding learning plans (only $42.9 \%$ of the objects gave a positive answer to this question); and due to the lack of clear understanding of learning objectives, most objects (55.1\%) clearly stated that they could not achieve the established learning objectives through autonomous learning.

From the above data, it can be seen that students lack a clear understanding of the teachers' teaching objectives and their learning objectives, and they also fail to formulate their own learning plans. As a result, the majority of students have no confidence to complete their learning objectives.

3. Habits of autonomous learning

The dimension of autonomous learning habits mainly examines whether the objects have formed good autonomous learning habits. The survey on the dimension of autonomous learning habits mainly includes 5 aspects: whether students can actively adhere to autonomous learning, whether students can consciously cultivate their autonomous learning ability in the learning process, whether students can effectively use autonomous learning strategies in the process of autonomous learning, the degree of students' satisfaction with their autonomous learning strategies, and the best way to improve their autonomous learning ability.

There are five questions in this part of the questionnaire, the first four are single-choice questions while the last one is a multiple-choice question. The survey results of the first four questions are detailed in the figure below. 


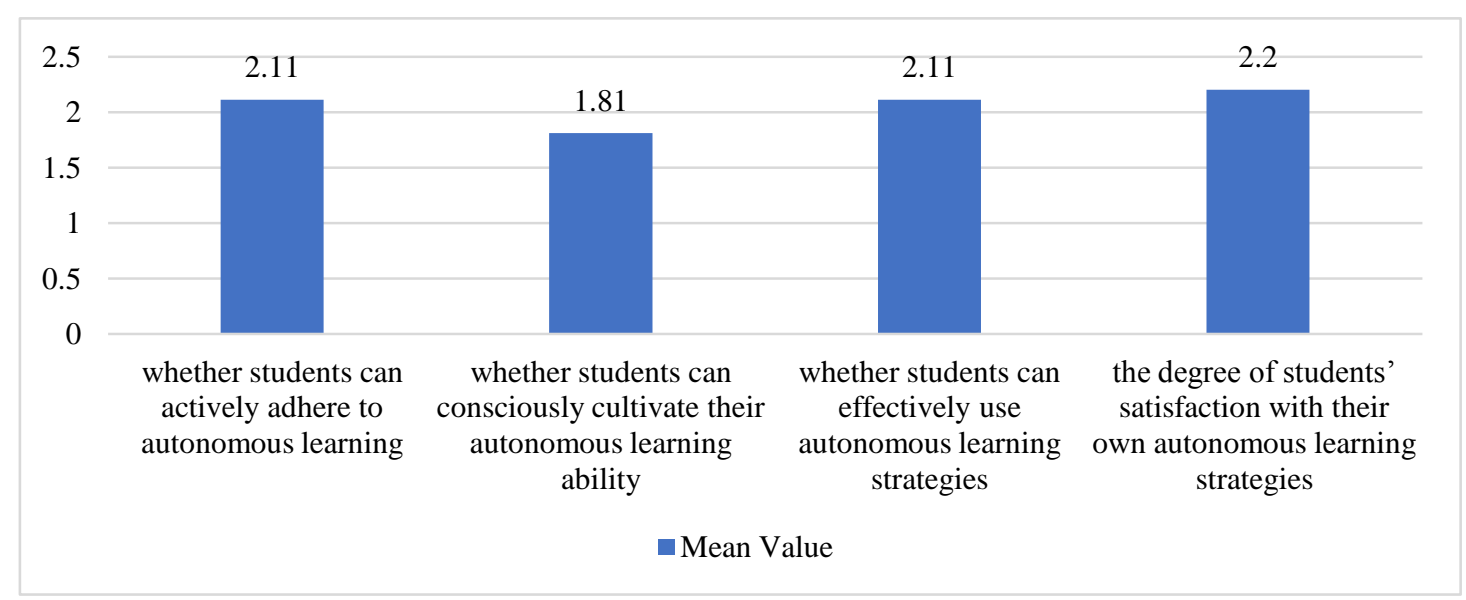

Figure 3 Investigation Results of the Third Dimension

It can be seen from Figure 3 that most students regarded that it was difficult to adhere to autonomous learning (only 29 students indicated that they were able to actively persist in autonomous learning, accounting for 14.6\%); in the process of autonomous learning, the vast majority of students $(75.8 \%)$ never consciously cultivated their autonomous learning ability; nor have they used autonomous learning strategies effectively (only $12.6 \%$ of the objects gave a positive answer to this question). Therefore, the vast majority of students were not satisfied with their autonomous learning strategies (the number of objects who selected "unsatisfied" was 62, accounting for 31.3\%; the number of objects who selected "very dissatisfied" was 74, accounting for $37.4 \%$ ).

The last question in the third dimension adopted a multiple-choice question to investigate students' main ways to improve their autonomous learning ability, and the result showed that $63.6 \%$ of the objects thought that teachers should provide scientific guidance in this aspect, $59.6 \%$ of the objects believed that more exercises should be done to help them cultivate autonomous learning ability, $31.8 \%$ of the objects thought that more examinations should be added to urge students to study independently, while $13.6 \%$ of the objects thought that online counseling could be very useful.

The above data show that students from application-oriented universities generally do not form a good habit of autonomous learning, nor do they have effective autonomous learning methods. In other words, they do not have the ability of autonomous learning in a strict sense.

4. Ability of self-monitoring

The self-monitoring dimension mainly examines whether the objects can effectively monitor and evaluate their autonomous learning. The survey of the self-monitoring dimension mainly includes 3 aspects: whether students can monitor and evaluate their autonomous learning, the main problems that students encounter in the process of autonomous learning, and the main factors affecting the development of students' autonomous learning ability.

There are three questions in this part of the questionnaire, the first one is a single-choice question, and the last two are multiple-choice questions. The results showed that students generally believed that it was difficult to effectively monitor and evaluate themselves in the process of autonomous learning (the mean value was as low as 1.91). Among the main problems that students encountered in the process of autonomous learning, $65.2 \%$ of the objects chose "lack of interest and motivation", $76.8 \%$ of the objects chose "lack of effective learning methods and strategies", $52.0 \%$ of them chose "lack of teachers' guidance", while 30.3\% of the objects thought that they were lack of satisfying learning environment. Among the main factors affecting the development of students' autonomous learning ability, $35.9 \%$ of the students thought that their academic foundation was weak and they were lack of confidence, $57.1 \%$ of the students said that they "had no effective learning methods and cannot understand the knowledge points through autonomous learning", $58.6 \%$ of the objects stated that "learning atmosphere" was very important, while $28.3 \%$ of the objects attributed this problem to "the lack of corresponding autonomous learning management system in universities".

The above data show that the vast majority of the objects have a strong desire to develop their autonomous learning ability, but the desire is in conflict with the actual academic level of students. From the perspective of students, to carry out effective autonomous learning, they must first have the ability to learn independently, and the confidence to carry out autonomous learning, and then it's also very important to find a method of autonomous learning that suits them. However, students in application-oriented universities generally have a poor academic foundation, and they do not have the basis of autonomous learning. Therefore, teachers should teach students in accordance with their aptitude in the teaching process. They should not only teach students the methods of autonomous learning but also supervise students' autonomous learning activities after class. Only in this way can students have the confidence to learn by themselves, and gradually improve their autonomous learning ability.

\section{DisCUSSION OF THE DEEP-SEATED REASONS FOR COLLEGE STUDENTS' LACK OF AUTONOMOUS LEARNING ABILITY}

From the survey in the previous chapter, it can be seen that students in application-oriented universities generally lack the ability of autonomous learning. To change this phenomenon and cultivate students' autonomous learning 
ability, first of all, the deep-seated reasons for students' lack of autonomous learning ability must be explored. Only in this way can we find the most suitable ways to solve the stubborn problems that hinder students' sustainable development.

Generally speaking, the reasons that affect the development of college students' autonomous learning ability can be summarized as the following four points: the achievement-oriented teaching philosophy, the knowledge-based curriculum setting, the teacher-centered teaching mode, and the summative-assessment-based course evaluation system.

\section{A. Achievement-oriented Teaching Philosophy}

The teaching philosophy is the concentrated embodiment of people's understanding of the internal laws of teaching and learning activities, and it also reflects people's attitudes towards teaching activities. A teaching philosophy is very important because it is the guiding ideology and action guide for people to engage in teaching activities. In other words, teaching behavior is dominated by teaching philosophy (Sun \& Fu, 2004). In layman's terms, "attitude decides everything."

In application-oriented universities, the achievement-oriented teaching philosophy occupies an important position. This kind of teaching philosophy seriously hinders the cultivation of students' autonomous learning ability. First of all, the achievement-oriented teaching philosophy is easy to cause students to misunderstand the purpose of learning. Under the guidance of this teaching philosophy, students' academic performance has become the main criterion for evaluating their learning effect, and the main purpose of students' learning is to pass the exam. It is under the influence of such misconceptions that students attach great importance to scores, and even choose to cheat in exams for high scores. Secondly, the achievement-oriented teaching philosophy will affect students' judgment of the importance of autonomous learning ability. Students mistakenly believe that the purpose of learning is to acquire knowledge and get high scores, rather than to develop the ability to learn knowledge independently. This has caused students to ignore the cultivation of autonomous learning ability for a long time. Finally, the achievement-oriented teaching philosophy will affect college students' judgment of their learning performance and imperceptibly urge college students to regard scores as the only way to evaluate themselves. However, if students only judge their learning effect according to their grades, they will not be able to have a full knowledge of their learning, let alone make effective adjustments to the problems that arise in their learning process.

\section{B. Knowledge-based Curriculum Setting}

Knowledge-based education narrows the original broad concept of education and equates knowledge teaching with education itself. The knowledge-based curriculum setting tends to emphasize theory rather than practice, and therefore general education courses and practice courses usually account for a relatively low proportion of the curriculum system.

Although this kind of curriculum system has enhanced the theoretical knowledge level of college students to a certain extent, it ignores the cultivation of their practical ability, therefore, it has been criticized for many years. On the one hand, the knowledge-based curriculum system mainly focuses on the imparting of theoretical knowledge, and students need to memorize knowledge points in the learning process. Due to the lack of practical opportunities, students' learning enthusiasm has been greatly affected over time. Students are not willing to conduct independent learning or take the initiative to explore knowledge but hope to cram before the exam. The inevitable result is that students not only fail to master the method of acquiring knowledge, but even the knowledge they have learned is also forgotten easily after exams, and the cultivation of critical thinking ability is even more impossible. On the other hand, the knowledge-based curriculum system encourages students' speculative psychology. Most students are not willing to focus on learning. If things go on like this, students would become more and more impetuous, which obviously goes against the original intention of higher education.

\section{Teacher-centered Teaching Mode}

The "teacher-centered" teaching mode emphasizes the leading role of teachers in teaching and maximizes the value of classroom teaching. However, this kind of teaching mode can easily ignore students' subjective initiative, which leads to students' lack of initiative and enthusiasm in learning. What's worse, it may even result in students' weariness of learning. In the teacher-centered teaching mode, teachers habitually conduct cramming teaching, and students are accustomed to passively accepting knowledge. They seldom carry out autonomous learning, and never try to solve problems independently, let alone actively explore the nature of the problem. Over time, students are used to asking others for help whenever they encounter problems or choosing to give up, which is obviously harmful to their long-term development.

\section{Summative-assessment-based Course Evaluation System}

Summative assessment refers to the summative evaluation of students' learning effect at the end of teaching activities. In application-oriented universities, summative evaluation still occupies a dominant position. In the process of learning evaluation, teachers often overemphasize the assessment of theoretical knowledge but pay less attention to the evaluation of students' initiative and creativity in the process of learning. This kind of curriculum evaluation ignores the progress made by students in the learning process and weakens the students' initiative and self-confidence. Under the guidance of this wrong orientation, the goal of students' learning is to get high scores, and the cultivation of students' 
autonomous learning ability and critical thinking ability has not been given due attention. The talents cultivated under such an evaluation system obviously cannot meet the requirements of "lifelong learning" for talents in today's society.

\section{Countermeasures to Cultivate College Students’'Autonomous Learning AbiLity}

Given the various reasons for college students' lack of autonomous learning ability, this chapter will put forward specific countermeasures to cultivate their autonomous learning ability from four aspects: teaching philosophy, curriculum setting, teaching mode, and evaluation system.

\section{A. Advocating the Process-oriented Teaching Philosophy}

The process-oriented teaching philosophy requires teachers should not only pay attention to students' academic performance but also need to make a comprehensive evaluation of the whole process of students' learning, so as to prompt students to timely adjust their learning attitudes and learning strategies according to the real-time feedback in the learning process.

First of all, the process-oriented teaching philosophy can guide students to better enjoy the learning process, remove the anxiety and correct their learning motivation. Only when students have established a correct learning attitude, can they truly become the masters of their learning, and improve their learning effects. Secondly, the process-oriented teaching philosophy enables students to focus on their daily performance. Students can determine their learning objectives, learning plans, and learning methods independently, and improve their autonomous learning ability.

\section{B. Setting the Competency-based Curriculum System}

The knowledge-based curriculum is not conducive to the development of college students' autonomous learning ability; therefore, the competency-based curriculum should be constructed. Competency-based education centers on ability cultivation, while not denying the status of knowledge accumulation. It develops ability on the basis of knowledge acquisition and at the same time, pays attention to the combination of theory and practice. As an application-oriented university, in the design of a curriculum system, the comprehensive needs of society, enterprises, and students should all be taken into consideration, so as to meet the requirements of society and enterprises for application-oriented talents to the greatest extent.

Firstly, the teaching objectives of the courses should be formulated based on students. In the teaching process, we should highlight the ability training objectives of courses, and advocate inquiry learning and interactive teaching. Secondly, the teaching content of the courses should meet the actual needs of enterprises. Therefore, in the design of talent training plans, it is necessary to consider what the market needs for talents, so as to help students better apply what they have learned into their daily practice after graduation. Thirdly, the proportion of practice courses should be increased. On the one hand, practice courses can help college students to deepen their understanding of theoretical and professional knowledge, so that they can better apply their knowledge to social practice; on the other hand, practice courses can enable teachers to devote more energy and time to question-answering. In this way, college students are encouraged to explore and research consciously and actively.

\section{Forming the Student-centered Teaching Mode}

The teacher-centered teaching mode inhibits students' learning initiative and is not conducive to the cultivation of their autonomous learning ability. Therefore, the student-centered teaching mode should be adopted. In this teaching mode, students, as the protagonists in the classroom, grasp the initiative of learning, and the role of teachers is to help students become the best that they can be.

To begin with, the student-centered teaching mode enables students to change from the passive recipients of knowledge to the active explorers of knowledge. Teachers use the form of questioning, classroom discussion, and role-play to help students learn independently and construct knowledge actively. This kind of teaching mode returns the initiative of learning to students and guides them to learn to study and think independently. Secondly, the student-centered teaching mode strives to treat students as independent individuals, and help everyone to fully develop their potential. Each student is a unique individual, and their learning styles, learning habits, learning rhythms are largely different, which determines that we cannot copy the assembly line operation mode to cultivate talents on a large scale. The student-centered teaching mode allows students to learn autonomously at their own pace, and teachers are responsible to guide and supervise them, thus ensuring the greatest possible stimulation of students' potential. Thirdly, the student-centered teaching mode also puts forward higher requirements for teachers. Teachers no longer mechanically repeat what the book says, but need to design flexible classroom activities to stimulate students' interest in learning and enhance their learning effect. This is undoubtedly beneficial to the development of teachers' comprehensive ability.

\section{Constructing the Formative-assessment-based Course Evaluation System}

Formative assessment is a comprehensive evaluation of students' daily performance, academic performance as well as their changes in learning attitudes and learning strategies during the learning process. It is a developmental evaluation based on the continuous observation, recording, and reflection of the whole learning process of students. Its purpose is to encourage students to learn actively and help students effectively monitor their learning process, so that 
students could gain a sense of achievement in learning. Formative evaluation transforms students from the object of evaluation to the subject and active participant of evaluation.

Compared with summative evaluation, formative evaluation has obvious advantages. Firstly, the formative evaluation adopts diversified evaluation methods, which include not only final examination but also extracurricular reading reports, classroom discussion, autonomous learning, and so on. Secondly, the evaluation content of the formative assessment is multifaceted. Besides the assessment of the theoretical knowledge, it also involves the assessment of students' learning attitudes, classroom participation, team-work capability, problem-solving ability, and so on. Thirdly, the evaluation subjects of formative assessment are more abundant. In the traditional way of evaluation, teachers are the only subject of evaluation, while in the formative evaluation, students themselves, their classmates, and teachers all need to participate in the evaluation process. Fourthly, formative assessment can provide real-time feedback to the teaching and learning process. This evaluation method can give dynamic feedback to the problems existing in teachers' teaching and students' learning, thereby promoting the improvement of teachers' teaching ability and students' academic performance. The above-mentioned advantages of formative assessment can help students to foster correct learning attitudes, raise problem awareness and enhance the ability of autonomous learning.

\section{CONCLUSION}

The cultivation of autonomous learning ability is in line with the actual needs of students' sustainable development. The progress of science and technology has not only enriched the content of knowledge but also increased the speed of knowledge update. The knowledge one gains in school is far from satisfying his needs for future development. Learning is no longer limited by time and space, and lifelong learning has become a quality and ability that contemporary people must possess. However, the learning effect depends on the learner's autonomous learning ability to a great extent. As teachers, we should realize that the long-term development of students is inseparable from the cultivation of their autonomous learning ability, since autonomous learning is the main way for individuals to study after they leave school. If a student lacks autonomous learning ability, his lifelong development will be greatly limited. However, at present, the self-learning ability of students in application-oriented universities is generally weak. Therefore, as educators, we have a long way to go.

\section{REFERENCES}

[1] Dickinson L. (1995). Autonomy and motivation a literature review. System 23.2, 165-174.

[2] Holec H. (1981). Autonomy and foreign language learning. Oxford: Pergamon Press.

[3] Littlewood W. (1996). Autonomy: an anatomy and framework. System 24.4, 427-435.

[4] Ministry of Education of the People's Republic of China. (2019). The implementation opinions of the Ministry of Education on the construction of first-class undergraduate courses. Gazette of the State Council of the People's Republic of China 10, 45-50.

[5] Sun Y. L \& Fu C. (2004). A discrimination of teaching philosophy. Journal of Yunnan Normal University 4, 133-136.

[6] Xu J. F. (2004). Investigation and analysis of autonomous English learning ability of non-English majors. Foreign Language Teaching and Research 1, 64-68.

Lingling Lou was born in Shaoxing, Zhejiang province, China in 1985. She received her master's degree from China University of Geoscience, China in 2010. She is currently a lecturer in the School of English Language, Zhejiang Yuexiu University, China. Her research interests include English teaching and cross-cultural communication. 